\title{
A Case of Insulinoma With Provoked Seizures for the Past Fourteen Years: A Case Report
}

\author{
Hoda Kadkhodazadeh, ${ }^{1}$ Muhanna Kazempour,, ${ }^{2}$ and Babak Salevatipour ${ }^{3}$ \\ ${ }^{1}$ Department of Endocrinology, Shahid Beheshti University of Medical Sciences, Tehran, IR Iran \\ ${ }^{2}$ Department of Internal Medicine, Shahid Beheshti University of Medical Sciences, Tehran, IR Iran \\ ${ }^{3}$ Department of Radiology, Shahid Beheshti University of Medical Sciences, Tehran, IR Iran \\ "Corresponding author: Muhanna Kazempour, Department of Internal Medicine, Shahid Beheshti University of Medical Sciences, Tehran, IR Iran. Tel: +98-2122439982, Fax: \\ +98-2122439784, E-mail: muhannakazempour@gmail.com
}

Received 2015 September 01; Accepted 2015 November 13.

\begin{abstract}
Introduction: Insulinoma is one of the most common neuro-endocrine tumors of the pancreas. Some cases with insulinoma present neuropsychiatric symptoms and are often misdiagnosed as psychosis thus patients may remain symptomatic from one week to as long as several decades before diagnosis.

Case Presentation: A 68-year-old male patient, who presented episodic seizures and a normal Electroencephalography (EEG) recording for the past fourteen years, had referred for evaluation of hypoglycemia. His biochemical profile revealed blood glucose of $45 \mathrm{mg} / \mathrm{dL}$. His C-peptide and insulin levels were elevated. Endoscopic pancreatic ultrasonography (EUS) revealed two mass lesions in pancreatic head. Pathological evaluation revealed well-differentiated endocrine neoplasm and granulomatous reaction in lymph nodes. After resection of the tumor, his symptoms resolved and he became seizure free.

Conclusions: Some cases with insulinoma that present neuropsychiatric symptoms might remain symptomatic for several decades before diagnosis. Therefore, it is important for physicians to be aware of presentations of insulinoma to avoid diagnostic delays.
\end{abstract}

Keywords: Hypoglycemia, Insulinoma, Seizure

\section{Introduction}

Insulinomas are the most common pancreatic islet cell tumors that arise from the beta cells within the islets of the Langerhans, but are not the only cause of endogenous hyperinsulinemic hypoglycemia (1). Patients with an insulinoma typically have a history of episodes of neuroglycopenia occurring in the postabsorptive (fasting) state. However, an appreciable subset of patients (6\% in one series) has reported symptoms exclusively in the postprandial state. Insulinomas are rare; an incidence of 1 in 250000 patients per year has been reported. Long-term survival is the rule after successful surgical removal of an insulinoma (2). We report on a 68-year-old male that presented episodic seizures and a normal Electroencephalography (EEG) recording for the past fourteen years, who was referred for evaluation of hypoglycemia.

\section{Case Presentation}

The case was a 68-year-old non-diabetic male referred to our hospital with chief complaint of hypoglycemia. He had episodic seizures for the past fourteen years and because of increased frequency of seizures since three month ago, long term EEG monitoring was performed and revealed normal EEG recording of sleep and wakefulness. These attacks had been repeating with palpitation, diaphoresis and loss of consciousness in the morning. Also, the patient reported a recent weight gain. The family had noticed that his symptoms improved continuously within 30 minutes of taking dextrose IV, at each visit to the emergency room. His family checked his blood sugar and realized he had been having hypoglycemia during seizures. Upon admission, he had a body temperature of $36.5^{\circ} \mathrm{C}$, blood pressure of $110 / 70 \mathrm{mmHg}$, a pulse rate of $87 /$ minute and a respiratory rate of $19 /$ minute. His body mass index (BMI) was 34 and other physical exams were within the normal range. The serum glucose level was determined as $45 \mathrm{mg} / \mathrm{dL}$ (normal range, $70-110 \mathrm{mg} / \mathrm{dL}$ ). He was given $10 \%$ dextrose IV, and his symptoms resolved. Laboratory tests revealed that his C-peptide and insulin levels were elevated. C-peptide: $8.4 \mathrm{U} / \mathrm{mL}$ (normal range 1.1 - 4.4U/mL), insulin: $82 \mathrm{uIU} / \mathrm{mL}$ (normal range 2.2-21 uIU/mL) Adrenocorticotrophic Hormone (ACTH): $11.2(1.6-13.9)$, cortisol: 33 micg/dL (171 - $536 \mathrm{micg} / \mathrm{dL})$, Ca: 9.7 (8.5 - 10.5), P: 2.5 (2.7 - 
5), C-Reactive Protein (CRP)+ uric acid: 7.9 (3.6 - 7.7), Lactate Dehydrogenase (LDH): $515 \mathrm{Iu} / \mathrm{L}(200$ - $400 \mathrm{Iu} / \mathrm{L})$. The abdominopelvic computerized tomography(CT) scan with IV and oral contrast was performed and depicted two mass lesions; one of them measuring $20 \mathrm{~mm}$ in diameter between pancreatic head and duodenum, adjacent to IVC in favor of the peri-pancreatic lymph node and the other was a hyperdense mass measuring $19 \mathrm{~mm}$ in diameter in pancreatic head (Figure 1). Computerized-tomography (CT) scan depicted no evidence of gross invasion, or liver metastases. Endoscopic pancreatic ultrasonography revealed two partially hypoechoic heterogeneous well-defined mass lesions in pancreatic head about $25 \times 19 \mathrm{~mm}$ and $12 \times 10 \mathrm{~mm}$, and no associated regional lymph node was noted. At operation, a $2.5-\mathrm{cm}$ tumor and $4-\mathrm{cm}$ nodular lymph node in suprapancreatic region, were resected from the head of the pancreas. Pathological evaluation revealed a welldifferentiated insulinoma with low mitotic activity, and no capsular or vascular invasion evident. The lymphoid structure was infiltrated by granulomatous reaction composed of numerous epithelioid cells, fibroblasts and giant cells. Some of them had central necrosis. The patient reported complete resolution of his symptoms after surgery and became seizure free. He developed hyperglycemia in the postoperative period, with serum glucose levels as high as $300 \mathrm{mg} / \mathrm{dL}$ (normal range $70-110 \mathrm{mg} / \mathrm{dL}$ ). At his twoweek follow-up, his fasting blood glucose, insulin levels and C-peptide levels were $104 \mathrm{mg} / \mathrm{dL}$ (normal range 70 - 110 $\mathrm{mg} / \mathrm{dL}$ ), 7.1 pmol/liter (normal range, 6 -144 pmol/liter) and $0.26 \mathrm{U} / \mathrm{mL}$ (normal range $1.1-4.4 \mathrm{U} / \mathrm{mL}$ ), respectively.

\section{Discussion}

We report on a 68-year-old non-diabetic male presented with hypoglycemia. Our patient displayed several characteristics typical of insulinomas. He was frequently admitted to the neurology department with seizure during the 14 years. He always had normal EEG recording during this period. It is not uncommon for patients to have symptoms for several months to years before diagnosis, in part, because the diagnosis is not entertained by clinicians. This is presumed to be due to the rarity of pancreatic endocrine tumors.

The diagnosis of insulinoma is suggested by hyperinsulinemia in the presence of hypoglycaemia and, reversal of the symptoms by administration of glucose (Whipple's triad). Occasionally, a patient with an insulinoma may not fulfill these criteria even during a 72-hour fast, and a few have plasma insulin levels lower than $18 \mathrm{pmol} / \mathrm{L}(<3$ $\mu \mathrm{U} / \mathrm{mL}$ ) during hypoglycemia, yet plasma C-peptide levels are usually $0.2 \mathrm{nmol} / \mathrm{L}(0.6 \mathrm{ng} / \mathrm{mL})$ or higher, and plasma pro-insulin levels are usually $5.0 \mathrm{pmol} / \mathrm{L}$ or higher in such

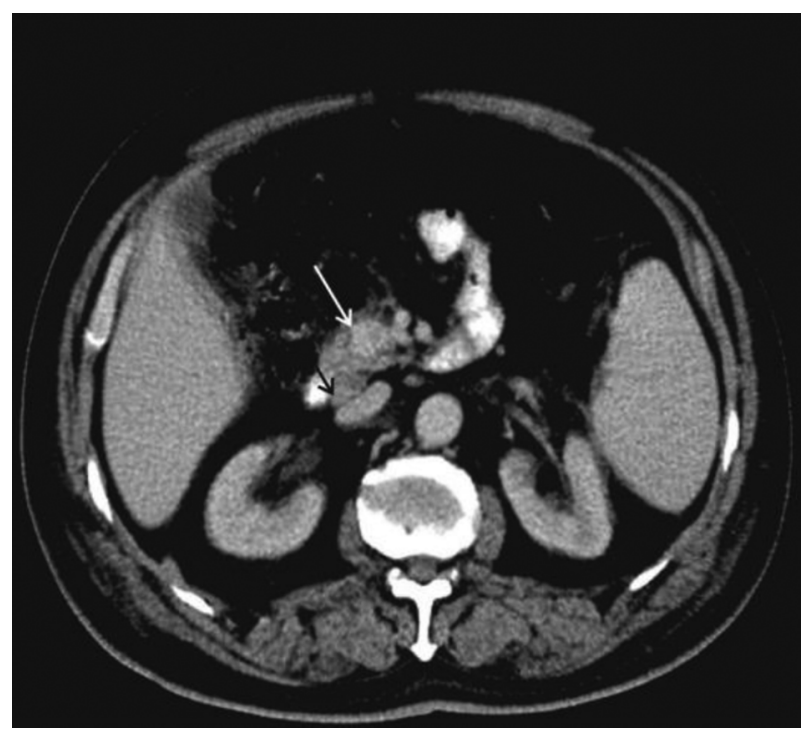

Figure 1. Abdominopelvic computerized tomography scan with IV and oral contrast revealed a hyperdense round mass in pancreatic head (white arrow) suggestive for neuroendocrine tumor. There was another ovoid isodense mass posterior to pancreatic head (black arrow) in favor of peri-pancratic lymph node.

patients (3). Once a clinical and biochemical diagnosis is established, the imaging modalities are used for localization of the tumor. Computed Tomography (CT), magnetic resonance imaging (MRI), and transabdominal ultrasonography detect approximately $75 \%$ of insulinomas $(1,4,5)$. Somatostatin receptor scintigraphy is some-what less sensitive (6). Endoscopic pancreatic ultrasonography (EUS), with the option of fine-needle aspiration of a detected tumor, has a sensitivity of greater than $90 \%(7,8)$. With the combination of noninvasive imaging and, if necessary EUS, preoperative localization of insulinoma has become the rule (1). Endoscopic pancreatic ultrasonography could not distinguish between insulinoma and lymph node in our case. However, pathology showed that only one of the lesions was insulinoma and other was lymph node. The majority of patients with insulinomas have lesions that are $1-2 \mathrm{~cm}$ in size, with $96 \%$ being less than $3 \mathrm{~cm}$ (9). The mean tumor size of insulinomas found in three of the largest reported series was $1.5 \mathrm{~cm}$, with a range of 0.1 to $7.0 \mathrm{~cm}$ (10-12). At operation of our case, a $2.5-\mathrm{cm}$ tumor and 4-cm nodular lymph node were resected from the head of the pancreas. The diagnosis of malignancy is based on the presence of metastases to the liver or regional lymph nodes or gross evidence of local invasion (13). Our case had no evidence of gross invasion, or liver metastases. At his two-week follow-up postoperatively, his fasting blood glucose, insulin levels and C-peptide levels were normal and he became seizure free. Long-term survival is the rule after 
successful surgical removal of an insulinoma (14).

\subsection{Conclusions}

Some cases with insulinoma that present neuropsychiatric symptoms may remain symptomatic several decades before diagnosis. Therefore, it is important for physicians to be aware of presentations of insulinoma to avoid diagnostic delays.

\section{Footnote}

Authors' Contribution: Our patient was admitted under the care of Hoda Kadkhodazadeh and Muhanna Kazempour, and was followed up in the outpatients' clinic. Muhanna Kazempour was the major contributor in writing the manuscript. Providing image and interpretation of CT was performed by Babak Salevatipour. All authors read and approved the final manuscript.

\section{References}

1. Placzkowski KA, Vella A, Thompson GB, Grant CS, Reading CC, Char boneau JW, et al. Secular trends in the presentation and management of functioning insulinoma at the Mayo Clinic, 1987-2007. J Clin Endocrinol Metab. 2009;94(4):1069-73. doi: 10.1210/jc.2008-2031. [PubMed: 19141587].

2. Service FJ, Natt N. The prolonged fast. J Clin Endocrinol Metab. 2000;85(11):3973-4. doi: 10.1210/jcem.85.11.6934. [PubMed: 11095416].
3. Vezzosi D, Bennet A, Fauvel J, Caron P. Insulin, C-peptide and proinsulin for the biochemical diagnosis of hypoglycaemia related to endogenous hyperinsulinism. Eur J Endocrinol. 2007;157(1):75-83. doi: 10.1530/EJE-07-0109. [PubMed: 17609405].

4. Noone TC, Hosey J, Firat Z, Semelka RC. Imaging and localization of islet-cell tumours of the pancreas on CT and MRI. Best Pract Res Clin Endocrinol Metab. 2005;19(2):195-211. doi: 10.1016/j.beem.2004.11.013. [PubMed: 15763695].

5. Grossman $\mathrm{AB}$, Reznek RH. Commentary: imaging of islet-cell tumours. Best Pract Res Clin Endocrinol Metab. 2005;19(2):241-3. doi: 10.1016/j.beem.2004.11.002. [PubMed: 15763698].

6. Virgolini I, Traub-Weidinger T, Decristoforo C. Nuclear medicine in the detection and management of pancreatic islet-cell tumours. Best Pract Res Clin Endocrinol Metab. 2005;19(2):213-27. doi: 10.1016/j.beem.2004.09.001. [PubMed: 15763696].

7. Kumbasar B, Kamel IR, Tekes A, Eng J, Fishman EK, Wahl RL. Imaging of neuroendocrine tumors: accuracy of helical CT versus SRS. Abdom Imaging. 2004;29(6):696-702. doi: 10.1007/s00261-003-0162-3. [PubMed: 15162235].

8. Fritscher-Ravens A. Endoscopic ultrasound and neuroendocrine tumours of the pancreas. JOP. 2004;5(4):273-81. [PubMed:15254362].

9. Pasieka JL, McLeod MK, Thompson NW, Burney RE. Surgical approach to insulinomas. Assessing the need for preoperative localization. Arch Surg. 1992;127(4):442-7. [PubMed: 1558498].

10. Thompson NW, Czako PF, Fritts LL, Bude R, Bansal R, Nostrant TT, et al. Role of endoscopic ultrasonography in the localization of insulinomas and gastrinomas. Surgery. 1994;116(6):1131-8. [PubMed: 7985098].

11. Grant CS. Surgical aspects of hyperinsulinemic hypoglycemia. Endocrinol Metab Clin North Am. 1999;28(3):533-54. [PubMed: 10500930].

12. Doherty GM, Doppman JL, Shawker TH, Miller DL, Eastman RC, Gorden $\mathrm{P}$, et al. Results of a prospective strategy to diagnose, localize, and resect insulinomas. Surgery. 1991;110(6):989-96. [PubMed: 1745987].

13. Mittendorf EA, Liu YC, McHenry CR. Giant insulinoma: case report and review of the literature. J Clin Endocrinol Metab. 2005;90(1):575-80. doi: 10.1210/jc.2004-0825. [PubMed: 15522939].

14. Shlomo M, Kenneth SP, Reed L, Henry MK. Williams textbook of Endocrinilogy. 13 ed. Elsevier; 2015. 